\title{
«2\% Rabatt auf allen Einkäufen für Galexis-Neukunden»
}

\section{Wir gratulieren dem glücklichen Gewinner!}

Das Wellness-Wochenende für zwei Personen im

\section{Parkhotel Delta $\star \star \star \star \star$ Ascona}

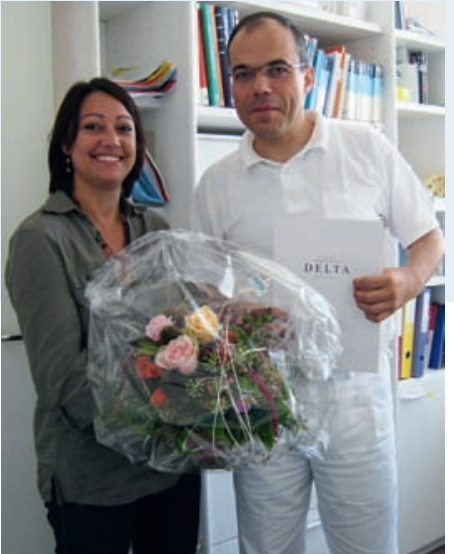

hat Dr. med. Thomas Clerc, Aadorf (rechts im Bild), gewonnen. Sandra Stadelmann von FMH Consulting Services (links im Bild) überreichte dem glücklichen Gewinner den Preis.

Dieser Preis wird gesponsert vom Parkhotel Delta Ascona.

Sie möchten Ihre Einkäufe auch über das Sammelrechnungssystem der FMH Consulting Services abwickeln lassen? Alle Neukunden profitieren im ersten Jahr auf allen Einkäufen bei unseren Vertragslieferanten von 2\% Rabatt.

Ihre Vorteile sind:

- einmalige, monatliche Rechnung für alle Bezüge bei Vertragslieferanten während der letzten 4-6 Wochen;

- Ihr administrativer Aufwand beschränkt sich auf eine Zahlung;

- weniger Bankspesen;

- die sorgfältig ausgesuchten Vertragslieferanten garantieren für erstklassige Leistungen und vorteilhafte Bedingungen.
So funktioniert es:

- Sie bestellen direkt bei unseren Vertragslieferanten;

- die Vertragslieferanten senden der FMH Consulting Services die monatliche Abrechnung zu;

- die FMH Consulting Services bezahlt am 20. des Folgemonats die Abrechnung;

- Sie erhalten jeweils am 15. des Monats eine Sammelrechnung.

\section{Antworttalon}

Vorname / Name

Adresse

PLZ/Ort

Telefon Privat

Telefon Geschäft

ZSR-Nummer (Konkordatsnummer)

E-Mail-Adresse

Ort/Datum/Unterschrift
O Ich möchte in Zukunft bei folgenden Lieferanten einkaufen und über das Sammelrechnungssystem abrechnen. Ich nehme davon Kenntnis, dass die Dienstleistung Sammelrechnung über die FMH Consulting Services für mich kostenlos ist.
O Aichele Medico AG, Aesch
O Apotheke zum Mörser, Zürich
O Dr. F. Rappai, Schlieren
O Galexis AG, Schönbühl
O IVF, Neuhausen
Lohmann \& Rauscher AG, Flawil
O Medicare AG, Zürich
O Mepha Pharma AG, Aesch BL
O Polymed Medical Center, Glattbrugg
O Raetus-Apotheke, Chur

O Rufma AG, Bremgarten
Salzmann AG, St. Gallen

S Spirig AG, Egerkingen

O Spiromed, Gelterkinden

O Streuli Pharma AG, Uznach

O Uneltech Electronic AG, Schwerzenbach

O Unitobler Apotheke, Bern 